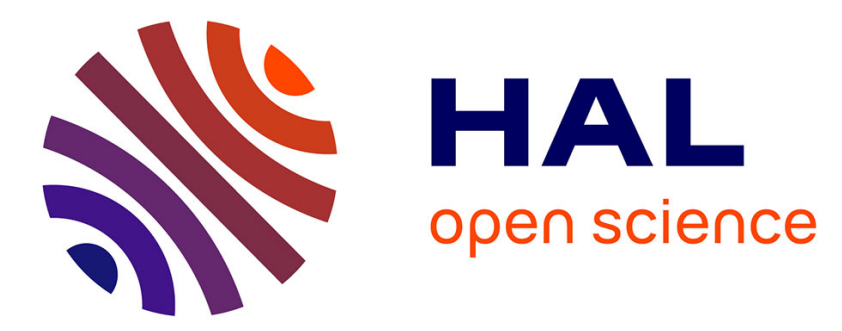

\title{
Isolation and properties of Lactococcus lactis subsp. lactis biovar diacetylactis CNRZ 483 mutants producing diacetyl and acetoin from glucose
}

H. Boumerdassi, Christophe C. Monnet, M. Desmazeaud, Georges Corrieu

\section{- To cite this version:}

H. Boumerdassi, Christophe C. Monnet, M. Desmazeaud, Georges Corrieu. Isolation and properties of Lactococcus lactis subsp. lactis biovar diacetylactis CNRZ 483 mutants producing diacetyl and acetoin from glucose. Applied and Environmental Microbiology, 1997, 63 (6), pp.2293-2299. hal-02697726

\section{HAL Id: hal-02697726 \\ https: / hal.inrae.fr/hal-02697726}

Submitted on 1 Jun 2020

HAL is a multi-disciplinary open access archive for the deposit and dissemination of scientific research documents, whether they are published or not. The documents may come from teaching and research institutions in France or abroad, or from public or private research centers.
L'archive ouverte pluridisciplinaire HAL, est destinée au dépôt et à la diffusion de documents scientifiques de niveau recherche, publiés ou non, émanant des établissements d'enseignement et de recherche français ou étrangers, des laboratoires publics ou privés. 


\title{
Isolation and Properties of Lactococcus lactis subsp. lactis biovar diacetylactis CNRZ 483 Mutants Producing Diacetyl and Acetoin from Glucose
}

\author{
HASSINA BOUMERDASSI, ${ }^{1}$ CHRISTOPHE MONNET, ${ }^{1 *}$ MICHEL DESMAZEAUD, ${ }^{2}$ \\ AND GEORGES CORRIEU ${ }^{1}$ \\ Laboratoire de Génie et Microbiologie des Procédés Alimentaires, Institut National de la Recherche Agronomique, \\ 78850 Thiverval Grignon, ${ }^{1}$ and Unité de Recherches Laitières, Institut National de \\ la Recherche Agronomique, 78350 Jouy-en-Josas, ${ }^{2}$ France
}

Received 21 February 1997/Accepted 10 March 1997

\begin{abstract}
Following treatment with the mutagen $N$-methyl- $N^{\prime}$-nitro- $N$-nitrosoguanidine, three mutants of Lactococcus lactis subsp. lactis biovar diacetylactis CNRZ 483 that produced diacetyl and acetoin from glucose were isolated. The lactate dehydrogenase activity of these mutants was strongly attenuated, and the mutants produced less lactate than the parental strain. The kinetic properties of lactate dehydrogenase of strain CNRZ 483 and the mutants revealed differences in the affinity of the enzyme for pyruvate, NADH, and fructose-1,6-diphosphate. When cultured aerobically, strain CNRZ 483 transformed $2.3 \%$ of glucose to acetoin and produced no diacetyl or 2,3-butanediol. Under the same conditions, mutants $483 \mathrm{~L} 1,483 \mathrm{~L} 2$, and $483 \mathrm{~L} 3$ transformed 42.0 , 78.9, and $75.8 \%$, respectively, of glucose to $\mathrm{C}_{4}$ compounds (diacetyl, acetoin, and 2,3-butanediol). Anaerobically, strain CNRZ 483 produced no $\mathrm{C}_{4}$ compounds, while mutants $483 \mathrm{~L} 1,483 \mathrm{~L} 2$, and $483 \mathrm{~L} 3$ transformed $2.0,37.0$, and $\mathbf{2 5 . 8 \%}$ of glucose to acetoin and 2,3-butanediol. In contrast to the parental strain, the NADH balance showed that the mutants regenerated most of the NAD via NADH oxidase under aerobic conditions and by ethanol production under anaerobic conditions.
\end{abstract}

Diacetyl is a major flavor compound in many cultured dairy products. This compound is synthesized primarily by leuconostocs and some lactococci that can metabolize citrate. Once a subject of controversy, the biosynthetic pathway of diacetyl is now well known. Citrate is transported inside cells by a citrate permease (22) and is then cleaved to acetate and oxaloacetate by citrate lyase. Oxaloacetate is decarboxylated by oxaloacetate decarboxylase, yielding pyruvate. $\alpha$-Acetolactate synthase transforms pyruvate to acetaldehyde-thiamine pyrophosphate and condenses it with a second molecule of pyruvate to form $\alpha$ acetolactate. Diacetyl originates from the chemical oxidative decarboxylation of $\alpha$-acetolactate $(15,24,43)$ and acetoin originates from the decarboxylation of $\alpha$-acetolactate by $\alpha$-acetolactate decarboxylase, by reduction of diacetyl by diacetyl reductase, or by nonoxidative chemical decarboxylation (23).

Since lactic acid bacteria produce relatively small quantities of diacetyl (generally less than $5 \mathrm{mg} / \mathrm{liter}$ ), considerable work has been devoted to increasing its production. Factors such as $\mathrm{pH}$, temperature $(4,32)$, citrate concentration $(28,33)$, and oxygen (3) have been studied for their effects on diacetyl production. Metabolic engineering strategies have also been proposed to obtain strains producing larger quantities of diacetyl. These strategies have aimed at overproduction or, on the contrary, at inactivating certain enzymes. McKay and Baldwin (29) isolated a mutant of Lactococcus lactis $\mathrm{C} 2$ which, in contrast to the parental strain, had very low lactate dehydrogenase activity. This enzymatic defect caused the mutant to produce diacetyl and acetoin at the expense of lactate. Kuila and Ranganathan (27) exposed L. lactis subsp. lactis biovar diacetylactis $\mathrm{S}_{1}$ to UV radiation and obtained mutants that produced a mean of 4.5 times more diacetyl and acetoin than the parental strain did. The mean lactate dehydrogenase activity of these

\footnotetext{
* Corresponding author. Phone: 331308154 91. Fax: 331308155 97. E-mail: monnet@cardere.grignon.inra.fr.
}

mutants was five times lower than that of the parental strain. In addition, Platteeuw et al. (36) and Gasson et al. (18) reported the inactivation of $L$. lactis lactate dehydrogenase by genetic engineering. The overexpression of $\alpha$-acetolactate synthase in L. lactis also leads to increased production of acetoin (36). Godon et al. (20) studied ilvBN genes encoding for an anabolic $\alpha$-acetolactate synthase involved in the synthesis of branchedchain amino acids (leucine, isoleucine, and valine). This enzyme has a higher affinity for pyruvate than catabolic $\alpha$-acetolactate synthase does (5). The overexpression of $i l v B N$ genes in L. lactis leads to diacetyl production that can reach $0.1 \mathrm{mM}$ in citrate-free medium. Several research groups have isolated an $\alpha$-acetolactate decarboxylase-negative strain from the high diacetyl-producing starter NIZO 4/25 $(26,38)$ or from Christian Hansen's D1 starter (30). In contrast to other L. lactis subsp. lactis biovar diacetylactis strains, this one accumulated $\alpha$-acetolactate in the culture medium. In the presence of oxygen, unstable $\alpha$-acetolactate undergoes an oxidative decarboxylation, favoring the production of diacetyl at the expense of acetoin $(24,30)$. Goupil et al. (21) proposed a method for selecting spontaneous $\alpha$-acetolactate decarboxylase mutants that was applicable to strains of $L$. lactis that were prototrophic for isoleucine and valine. $\alpha$-Acetolactate decarboxylase mutants were also obtained after mutagenesis with $N$-methyl- $N^{\prime}$ nitro- $N$-nitrosoguanidine (NTG) (31). Finally, the inactivation of the gene coding for $\alpha$-acetolactate decarboxylase by genetic engineering has been reported by Swindell et al. (39).

In light of the results described above, it is possible to employ different strategies to modify metabolic fluxes to obtain the overproduction of diacetyl. Recent work (7) reported the effect of adding citrate to L. lactis subsp. lactis biovar diacetylactis CNRZ 483 grown in a whey-based medium. The bioconversion yield of citrate to diacetyl and acetoin decreased considerably as the citrate concentration was increased. The authors thus envisaged the possibility of selecting lactococci 
that could produce diacetyl and acetoin from sugars in the absence of citrate. The present work describes a method for selecting this type of mutant, followed by characterization in terms of glucose metabolism in the presence and absence of oxygen. The kinetics of lactate dehydrogenase, the enzyme responsible for the substantial shunt of metabolic flux in these mutants, were also studied.

\section{MATERIALS AND METHODS}

Strain. L. lactis subsp. lactis biovar diacetylactis CNRZ 483 was obtained from the lactic acid bacteria collection of the Institut National de la Recherche Agronomique (Jouy-en-Josas, France). Stock cultures were obtained after incubating the strain for $15 \mathrm{~h}$ at $30^{\circ} \mathrm{C}$ in MRS medium (16) and inoculating $1.5 \mathrm{ml}$ of the culture in $10 \mathrm{ml}$ of MRS containing $15 \%$ (vol/vol) glycerol. They were stored without previous incubation at $-80^{\circ} \mathrm{C}$.

Obtaining mutants. Strain CNRZ 483 was grown in $5 \mathrm{ml}$ of MRS broth. At the end of logarithmic growth, the culture was centrifuged $(2,500 \times g, 10 \mathrm{~min})$ and washed twice with $100 \mathrm{mM}$ potassium phosphate buffer $(\mathrm{pH} 7)$. The bacteria were then resuspended in $1 \mathrm{ml}$ of a solution of NTG (Aldrich, St. Quentin Fallavier, France) at a final mutagen concentration of $50 \mu \mathrm{g} / \mathrm{ml}$. At this concentration, the mortality rate caused by NTG was close to $90 \%$. After $1 \mathrm{~h}$ of incubation at $30^{\circ} \mathrm{C}$, the bacteria were washed in buffer and incubated for $2 \mathrm{~h}$ at $30^{\circ} \mathrm{C}$ in MRS broth. They were then homogenized aseptically with an UltraTurrax apparatus (IKA, Labortechnik, Stafen, Germany) for 2 min at 20,000 rpm to break the chains. Two hundred 14-mm-diameter petri dishes were inoculated to obtain about 150 colonies per plate. The agar medium used was a derivative of M17 (41), composed of agar (15 g/liter), tryptone ( $2.5 \mathrm{~g} /$ liter $)$, peptic digest of meat ( $2.5 \mathrm{~g}$ /liter), papain digest of soybeans ( $5 \mathrm{~g} /$ /iter $)$, sodium glycerophosphate (19 g/liter), L-ascorbic acid (0.5 g/liter), yeast extract ( $2.5 \mathrm{~g} /$ liter $)$, and magnesium sulfate $(0.25 \mathrm{~g} /$ /iter $)$. The $\mathrm{pH}$ of the medium was adjusted to 7 with hydrochloric acid, and glucose (5 g/liter) was added aseptically after autoclaving the agar medium at $110^{\circ} \mathrm{C}$ for $15 \mathrm{~min}$

After $72 \mathrm{~h}$ of incubation at $30^{\circ} \mathrm{C}$, replica plating on felt was carried out because the screening used was lethal for the bacteria. The screening system involved detecting clones that could produce diacetyl and acetoin from glucose in the absence of citrate. These compounds were detected directly on the plates by use of a procedure adapted from Phalip et al. (35). A solution containing $50 \mathrm{~g}$ of agar (OSI, Maurepas, France) per liter and $5 \mathrm{~g}$ of creatine (Sigma, St. Quentin Fallavier, France) per liter was boiled, cooled to $60^{\circ} \mathrm{C}$, and then mixed in a proportion of 3:1 (vol/vol) with a freshly prepared solution of $\alpha$-naphthol (Sig$\mathrm{ma}$ ) at $75 \mathrm{~g} / \mathrm{l}$ in $2.5 \mathrm{M}$ sodium hydroxide. Screening was done under a ventilated hood by spreading a $20-\mathrm{ml}$ overlay uniformly on the surface of each petri dish. After the agar solidified ( $30 \mathrm{~min})$, the plates were examined on a light table and clones forming a red halo were recovered from the replicas.

Identification of mutants. Putative mutants were identified to verify that they were not contaminants. API $50 \mathrm{CH}$ strips (BioMérieux, Marcy l'Etoile, France) and the randomly amplified polymorphic DNA (RAPD) method (45, 47), adapted by Tailliez et al. (40), were used for this. Three primers were used, namely, B06 $\left({ }^{5^{\prime}} \mathrm{TGCTCTGCCC}^{3^{\prime}}\right), \mathrm{B} 07\left({ }^{5^{\prime}} \mathrm{GGTGACGCAG}^{3^{\prime}}\right)$, and B10 $\left({ }^{5^{\prime} \mathrm{CT}}\right.$ GCTGGGAC $\left.^{3^{\prime}}\right)$.

Culture medium and conditions. To characterize the mutants obtained, cultures were grown in the absence and presence of oxygen. The medium used was identical to that used for screening except for the absence of agar. Anaerobic cultures were prepared in 1-liter conical flasks containing 1 liter of medium inoculated at $3 \%$ (vol $/ \mathrm{vol})$. Conditions of anaerobiosis within the flasks were maintained by permanently bubbling with nitrogen $(250 \mathrm{ml} / \mathrm{h})$. Aerated cultures were grown in 2-liter conical flasks containing $500 \mathrm{ml}$ of medium inoculated at $3 \%$ (vol/vol). The flasks were incubated on a shaker at $200 \mathrm{rpm}$. All cultures were incubated at $30^{\circ} \mathrm{C}$

Analysis of biomass, products, and metabolites. The absorbance of cultures at $575 \mathrm{~nm}$ was measured with a spectrophotometer (UV-160; Shimadzu, Kyoto, Japan). Cultures with an $A_{575}$ higher than 0.6 were diluted in sterile medium. Dry weight (in grams per liter) was calculated from the $A_{575}$ by using the correlation of $1 A_{575}$ unit equal to $0.51 \pm 0.02 \mathrm{~g}$ (dry weight). Diacetyl and acetoin were assayed by the colorimetric method of Walsh and Cogan (44). $\alpha$-Acetolactate was assayed by the colorimetric method described by Monnet et al. (30). Glucose, L-lactate, acetate, pyruvate, ethanol, acetaldehyde, and formate were assayed with Boehringer (Mannheim, Germany) kits. The concentrations of 2,3butanediol were determined by high-performance liquid chromatography with the method described by Bassit et al. (3).

Assays of enzymatic activities. At the end of growth, culture media were centrifuged at $14,000 \times \mathrm{g}$ for $15 \mathrm{~min}$ at $+4^{\circ} \mathrm{C}$. After washing in $50 \mathrm{mM}$ sodium phosphate buffer $(\mathrm{pH} 7)$, the bacteria were resuspended $(1: 20, \mathrm{vol} / \mathrm{vol})$ in the same buffer and treated five times in a Branson (Carouge-Geneva, Switzerland) sonifier for $1 \mathrm{~min}$ at $0^{\circ} \mathrm{C}$ and $50 \mathrm{~W}$. After another centrifugation $(14,000 \times g$ for $30 \mathrm{~min}$ ), enzymatic activities were determined in the supernatant. Lactate dehydrogenase was measured by monitoring the decrease in $A_{340}$ (11). The assay was performed in $50 \mathrm{mM}$ Tris-maleate buffer $(\mathrm{pH}$ 7) containing $100 \mu \mathrm{l}$ of cell extract, $10 \mathrm{mM}$ sodium pyruvate, $1 \mathrm{mM}$ fructose-1,6-diphosphate, and $0.15 \mathrm{mM}$ NADH
(42). Acetoin and diacetyl reductase were measured as described by Cogan (11) These enzyme activities were corrected for NADH oxidase activities, determined under the same conditions, but in the absence of substrate (pyruvate, diacetyl, and acetoin for lactate dehydrogenase, diacetyl reductase, and acetoin reductase, respectively). NADH oxidase activities given below (see Table 4) were measured with $0.13 \mathrm{mM}$ NADH as described by Anders et al. (2). One enzyme unit was defined as $1 \mu \mathrm{mol}$ of NADH oxidized $\min ^{-1}$. $\alpha$-Acetolactate synthase activity was determined by measuring acetoin production from pyruvate (11). The reaction mixture contained $100 \mu \mathrm{l}$ of cell extract, $80 \mathrm{mM}$ sodium pyruvate, and 0.21 $\mathrm{mM}$ thiamine pyrophosphate in $100 \mathrm{mM}$ sodium phosphate buffer $(\mathrm{pH} 6.5)$ After $15 \mathrm{~min}$ of incubation at $45^{\circ} \mathrm{C}, 200 \mu \mathrm{l}$ of $0.5 \mathrm{M} \mathrm{HCl}$ was added to stop the reaction and to convert $\alpha$-acetolactate to acetoin. The acetoin formed was then measured by the colorimetric method of Westerfeld (46). $\alpha$-Acetolactate decarboxylase activity was measured as described previously (34) under optimal conditions with $50 \mathrm{mM} \mathrm{D}-\alpha$-acetolactate and in the presence of $40 \mathrm{mM}$ L-leucine. One unit of $\alpha$-acetolactate synthase ( $\alpha$-acetolactate decarboxylase) activity was defined as the formation of $1 \mu \mathrm{mol}$ of $\alpha$-acetolactate (acetoin) per min. Protein concentrations were determined by the method of Bradford (8), with bovine serum albumin as standard protein.

Lactate dehydrogenase kinetics. The effect of pyruvate, NADH, and fructose1,6-diphosphate concentrations on the activity of lactate dehydrogenase from strain CNRZ 483 and its mutants was determined. The apparent $K_{m}$ was defined as that substrate concentration at which velocity was half of the maximum $\left(V_{\max }\right)$. Lactate dehydrogenase activity was measured as described above. A special optical glass cell with a 1-mm pathlength (Hellma 100-OS; Polylabo, Strasbourg, France) enabled concentrations of NADH higher than $0.15 \mathrm{mM}$ to be tested.

\section{RESULTS}

Obtaining mutants. After the mutagenesis of L. lactis subsp. lactis biovar diacetylactis CNRZ 483, 30,000 colonies were screened for potential production of diacetyl and acetoin from glucose. Three positive colonies were detected: one colony formed a weak red halo (483L1), and the halos of the other two colonies were intense (483L2 and 483L3). The biochemical characters of strain CNRZ 483 and of the three mutants (483L1, 483L2, and 483L3) were identical, as determined with API $50 \mathrm{CH}$ strips. Similarly, the RAPD profiles of the parental strain and the mutants were similar, with a percentage of similarity higher than $94 \%$ (results not shown). Thus, clones 483L1, 483L2, and 483L3 had the same origin as strain CNRZ 483.

Growth and production of metabolites by strain CNRZ 483 and the three mutants. Batch cultures in the presence and absence of oxygen were prepared to characterize the parent strain and mutants 483L1, 483L2, and 483L3. Bacterial growth and acidifying activity were monitored, and the principal metabolites of glucose metabolism were assayed (Fig. 1).

(i) Bacterial growth and acidification. Under anaerobic conditions, the final dry weight of strain CNRZ 483 and mutant 483L1, a reflection of total bacterial concentration, was close to $0.90 \mathrm{~g} /$ liter (Table 1) and was higher (about 30\%) for mutants 483L2 and 483L3. The growth rate of strain CNRZ 483 $\left(0.82 \mathrm{~h}^{-1}\right)$ was slightly higher than those of the three mutants, and the same trends were observed under aerobic conditions. In addition, the maximum growth rates of strains 483, 483L2, and 483L3 were lower under aerobic than anaerobic conditions.

The final $\mathrm{pH}$ of the medium after anaerobic growth of strain CNRZ 483 was 5.06, lower than that of mutants 483L1, 483L2, and 483L3 (Table 1). This effect was accentuated under aerobic conditions since the final $\mathrm{pH}$ increased for all the strains, in particular for mutants 483L2 and 483L3. This weak acidifying power could explain the higher final biomass. There is probably a lower degree of acid inhibition in these mutants.

(ii) Accumulation of metabolic products. Regardless of culture conditions, glucose $(\sim 26 \mathrm{mM})$ was totally consumed by all strains (Table 2). The three mutants produced less lactate than strain CNRZ 483 did anaerobically, in particular mutants 483L2 and 483L3, which produced $80 \%$ less than the parental strain. Higher ethanol production compensated for the de- 


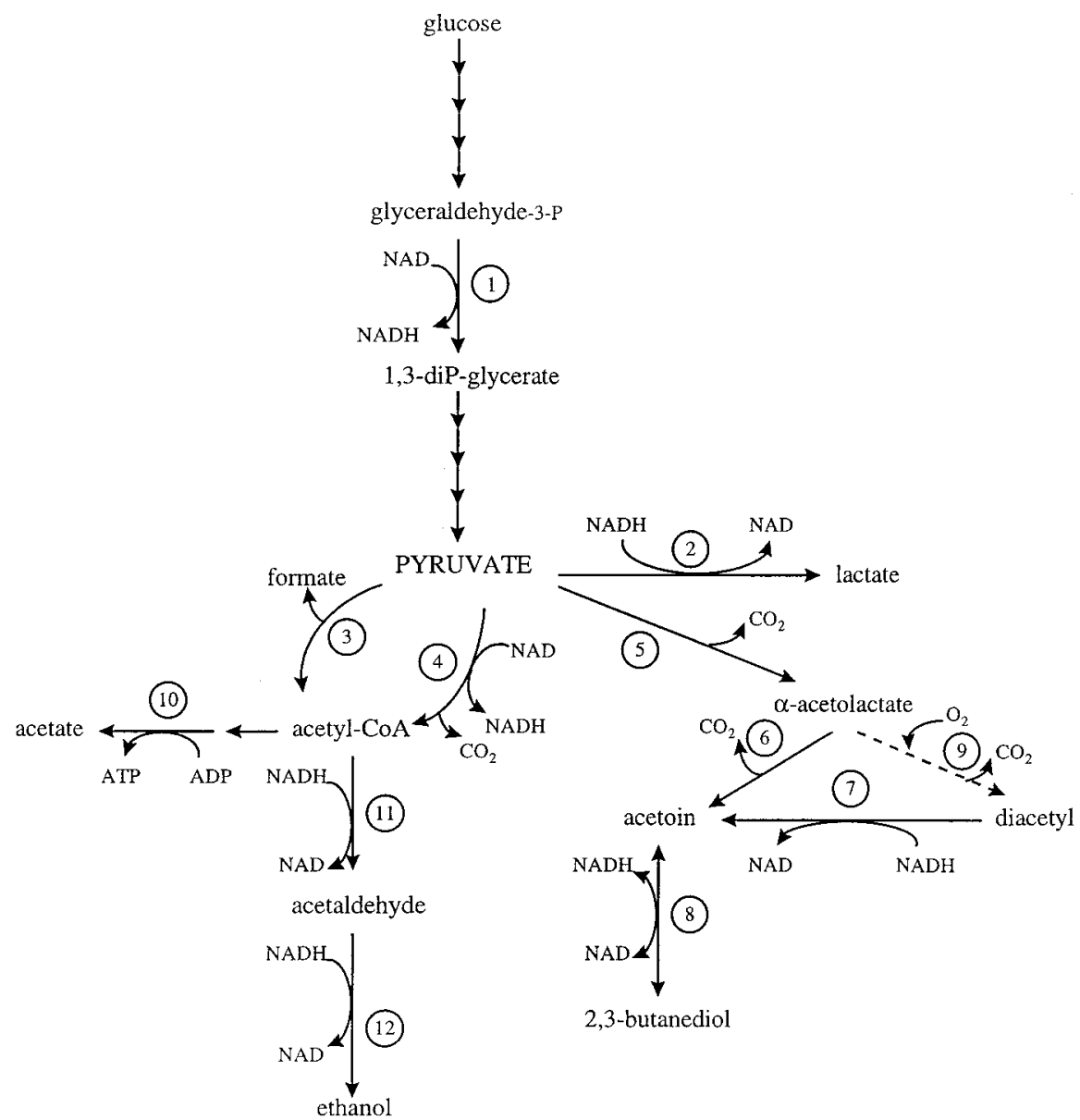

FIG. 1. Metabolic pathway showing the principal routes of glucose utilization by lactococci. 1, triose-phosphate dehydrogenase; 2 , lactate dehydrogenase; 3 , pyruvate formate lyase; 4, pyruvate dehydrogenase; 5, $\alpha$-acetolactate synthase; $6, \alpha$-acetolactate decarboxylase; 7, diacetyl reductase; 8, acetoin reductase; 9, oxidative decarboxylation of $\alpha$-acetolactate; 10, acetate kinase; 11, aldehyde dehydrogenase; 12 , alcohol dehydrogenase. CoA, coenzyme A.

creased quantities of lactate produced by the three mutants. In contrast to the parental strain that produced very little ethanol $(0.7 \mathrm{mM})$, mutants $483 \mathrm{~L} 1,483 \mathrm{~L} 2$, and $483 \mathrm{~L} 3$ produced 4.6 , 20.0 , and $19.4 \mathrm{mM}$, respectively. In parallel, the quantity of formate produced by the mutants was also very high, in particular for 483L2 and 483L3. In the presence of oxygen, lactate production by all strains decreased. The three mutants also produced less ethanol and formate, while the parental strain produced none at all. Considerable production of diacetyl and acetoin from glucose compensated for the decreased production of ethanol and lactate by the mutants. Strain CNRZ 483 could not produce diacetyl from glucose, whereas the three mutants 483L1, 483L2, and 483L3 produced the compound $(0.2$ to $0.3 \mathrm{mM})$. In parallel, the three mutants produced 10.5 , 19.8 , and $19.2 \mathrm{mM}$ of acetoin, respectively, while the parental strain produced only traces $(0.6 \mathrm{mM})$. Under anaerobic conditions, only mutants 483L2 and 483L3 still produced acetoin, at concentrations two to four times lower than that produced in the presence of oxygen. 2,3-Butanediol production was observed only for mutants 483L1, 483L2, and 483L3 grown anaerobically and for 483L2 and 483L3 grown in the presence of oxygen. The bioconversion yield of glucose to diacetyl, acetoin, and 2,3-butanediol (RB) was calculated as follows: $\mathrm{RB}=$ (diacetyl + acetoin $+2,3$-butanediol)/glucose. This yield in strain CNRZ 483 was limited to $2.3 \%$ under aerobic conditions and increased considerably in mutants $483 \mathrm{~L} 2$ and 483L3, reaching
78.9 and $75.8 \%$, respectively. In the presence or absence of oxygen, all strains produced only small quantities of acetaldehyde (maximum, $0.4 \mathrm{mM}$ ) and of pyruvate (maximum, 0.5 $\mathrm{mM}$ ). In parallel, no strain accumulated $\alpha$-acetolactate. As was observed by Cogan et al. (12), strain CNRZ 483 produced more acetate in the presence of oxygen, which was not the case for the mutants that produced less acetate under aerobiosis.

TABLE 1. Growth and acidification of L. lactis subsp. lactis biovar diacetylactis CNRZ 483 and mutants ${ }^{a}$

\begin{tabular}{lcccc}
\hline \multicolumn{1}{c}{ Strain } & $\mathrm{O}_{2}$ & $\begin{array}{c}\text { Biomass } \\
(\mathrm{g} / \text { liter })\end{array}$ & $\begin{array}{c}\mu_{\max } \\
\left(\mathrm{h}^{-1}\right)^{b}\end{array}$ & Final pH \\
\hline CNRZ 483 & - & 0.89 & 0.82 & 5.06 \\
$483 \mathrm{~L} 1$ & + & 1.02 & 0.71 & 5.45 \\
& - & 0.92 & 0.64 & 5.33 \\
$483 \mathrm{~L} 2$ & + & 1.02 & 0.69 & 6.01 \\
& - & 1.18 & 0.78 & 5.56 \\
$483 \mathrm{~L} 3$ & + & 1.19 & 0.59 & 6.46 \\
& - & 1.19 & 0.66 & 5.46 \\
& + & 1.23 & 0.59 & 6.44
\end{tabular}

${ }^{a}$ Strains were cultivated at $30^{\circ} \mathrm{C}$ in modified M17 broth in the presence $(+)$ or absence $(-)$ of oxygen.

${ }^{b}$ The maximum growth rate $\left(\mu_{\max }\right)$ was determined by the slope of a plot of ln absorbance versus time. 
TABLE 2. Glucose consumed and products formed by L. lactis subsp. lactis biovar diacetylactis CNRZ 483 and mutants ${ }^{a}$

\begin{tabular}{|c|c|c|c|c|c|c|c|c|}
\hline \multirow{2}{*}{ Measurement (unit) } & \multicolumn{2}{|c|}{ CNRZ 483} & \multicolumn{2}{|c|}{$483 \mathrm{~L} 1$} & \multicolumn{2}{|c|}{$483 \mathrm{~L} 2$} & \multicolumn{2}{|c|}{$483 \mathrm{~L} 3$} \\
\hline & $-\mathrm{O}_{2}$ & $+\mathrm{O}_{2}$ & $-\mathrm{O}_{2}$ & $+\mathrm{O}_{2}$ & $-\mathrm{O}_{2}$ & $+\mathrm{O}_{2}$ & $-\mathrm{O}_{2}$ & $+\mathrm{O}_{2}$ \\
\hline Glucose consumed (mM) & 26.0 & 26.5 & 25.9 & 25.5 & 26.0 & 26.6 & 26.0 & 26.0 \\
\hline L-Lactate $(\mathrm{mM})$ & 50.3 & 45.7 & 39.2 & 24.3 & 6.9 & 4.5 & 8.5 & 2.6 \\
\hline Ethanol $(\mathrm{mM})$ & 0.7 & $\mathrm{ND}^{b}$ & 4.6 & 3.3 & 20.0 & 3.9 & 19.4 & 1.6 \\
\hline Formate (mM) & 2.4 & ND & 4.3 & ND & 27.0 & 0.5 & 24.5 & 1.7 \\
\hline Diacetyl (mM) & ND & ND & ND & 0.2 & ND & 0.3 & ND & 0.2 \\
\hline Acetoin (mM) & ND & 0.6 & ND & 10.5 & 8.3 & 19.8 & 5.1 & 19.2 \\
\hline 2,3-Butanediol (mM) & ND & ND & 0.5 & ND & 1.3 & 0.9 & 1.6 & 0.3 \\
\hline Acetaldehyde $(\mathrm{mM})$ & 0.1 & 0.4 & 0.3 & 0.1 & 0.2 & 0.1 & 0.2 & 0.1 \\
\hline Pyruvate $(\mathrm{mM})$ & 0.5 & 0.5 & 0.2 & 0.2 & 0.1 & 0.4 & 0.4 & 0.4 \\
\hline Acetate $(\mathrm{mM})$ & 3.0 & 5.5 & 4.7 & 3.2 & 6.6 & 3.8 & 8.3 & 5.3 \\
\hline$\alpha$-Acetolactate $(\mathrm{mM})$ & ND & ND & ND & ND & ND & ND & ND & ND \\
\hline Theoretical $\mathrm{CO}_{2}(\mathrm{mM})^{c}$ & 1.4 & 7.1 & 6.3 & 28.0 & 19.0 & 49.3 & 16.8 & 44.7 \\
\hline Carbon balance $(\%)^{d}$ & 105.0 & 100.6 & 96.5 & 103.0 & 101.9 & 102.8 & 96.5 & 95.0 \\
\hline
\end{tabular}

${ }^{a}$ Strains were cultivated at $30^{\circ} \mathrm{C}$ in modified M17 broth in the presence or absences of oxygen $\left(+\mathrm{O}_{2}\right.$ and $-\mathrm{O}_{2}$, respectively). The values are means of at least three measurements. The standard error was lower than $5 \%$ for all compounds except 2,3-butanediol, where it was lower than $15 \%$.

${ }^{b} \mathrm{ND}$, not detectable.

${ }^{c}$ Theoretical $\mathrm{CO}_{2}=2 \times$ (diacetyl + acetoin $+2,3$-butanediol $)+$ (acetate + ethanol + acetaldehyde - formate $)$.

${ }^{d}$ Carbon balance calculated by taking into account theoretical $\mathrm{CO}_{2}$.

The theoretical production of $\mathrm{CO}_{2}$ by the different strains was calculated from the metabolic pathway (Fig. 1). Anaerobically, the mutants produced more $\mathrm{CO}_{2}$ than strain CNRZ 483 did (Table 2). All strains produced more $\mathrm{CO}_{2}$ under aerobic conditions, in particular mutants 483L2 and 482L3, which produced 49.3 and $44.7 \mathrm{mM} \mathrm{CO}$, respectively. The carbon balance was calculated from the different fermentation products arising from glucose metabolism. Recovered carbon varied from 95.0 to $105.0 \%$ as a function of the strains and culture conditions.

(iii) NADH balance. The quantities of NADH produced and consumed were calculated on the basis of the final concentrations of products of glucose metabolism (Table 3 ). Anaerobically, strains CNRZ 483 and 483L1 reoxidized 94.2 and $68.7 \%$, respectively, of the NADH produced by the lactate dehydrogenase-catalyzed formation of lactate. These strains also used ethanol and acetaldehyde biosynthetic pathways to regenerate NAD. Strains CNRZ 483 and mutant 483L1 reoxidized small quantities of NADH by ethanol formation (2.6 and $16.1 \%$, respectively). This mutant also reoxidized $0.9 \%$ of $\mathrm{NADH}$ by the formation of 2,3-butanediol. The levels of NADH reoxidized by lactate dehydrogenase in mutants 483L2 and 483L3 were limited to 13.3 and $15.3 \%$, respectively. On the other hand, more than $70 \%$ of the reduced coenzyme was reoxidized by ethanol formation. In addition, these mutants reoxidized a mean of $2.7 \%$ of the NADH resulting from 2,3-butanediol synthesis. The difference between NADH produced and consumed was between 3.0 and $13.8 \%$ of total NADH produced as a function of the strain. This excess could have resulted from the imprecision of certain assays and/or the existence of NADH reoxidation pathways not taken into account by our calculations. It cannot be attributed to NADH oxidase, since the cultures were grown in the absence of oxygen.

Under aerobic conditions, all of the strains reoxidized less $\mathrm{NADH}$ through the formation of lactate, ethanol, and acetaldehyde than under anaerobic conditions. Mutants 483L2 and 483L3 reoxidized 13.0 and $5.6 \%$, respectively, of the NADH produced by ethanol synthesis. The difference between the quantity of NADH produced and that consumed could be due to the participation of two enzymes not mentioned in Table 3 , i.e., NADH oxidase and diacetyl reductase. Nevertheless, it has been shown that the same enzyme, acetoin reductase, catalyzes the reduction of diacetyl (to acetoin) and of acetoin (to 2,3butanediol) $(13,19)$. In a mixture of acetoin and diacetyl, acetoin is the preferred substrate of acetoin reductase (23). There is thus probably less reoxidation of NADH via the transformation of diacetyl to acetoin than reoxidation due to the transformation of acetoin to 2,3-butanediol. Under aerobic

TABLE 3. Comparison of NADH balances in L. lactis subsp. lactis biovar diacetylactis CNRZ 483 and mutants ${ }^{a}$

\begin{tabular}{|c|c|c|c|c|c|c|c|c|c|c|}
\hline \multirow[b]{2}{*}{ Strain } & \multirow[b]{2}{*}{$\mathrm{O}_{2}$} & \multicolumn{3}{|c|}{ NADH produced (mM) } & \multicolumn{5}{|c|}{ NADH consumed (mM) } & \multirow[b]{2}{*}{ Difference $^{b}$} \\
\hline & & $\begin{array}{c}\text { Triose-P- } \\
\text { dehydrogenase }^{c}\end{array}$ & $\begin{array}{c}\text { Pyruvate } \\
\text { dehydrogenase }^{c}\end{array}$ & Total & $\begin{array}{c}\text { Lactate } \\
\text { dehydrogenase }{ }^{c}\end{array}$ & $\begin{array}{c}\text { Aldehyde } \\
\text { dehydrogenase }\end{array}$ & $\begin{array}{l}\text { Alcohol } \\
\text { reductase }^{c}\end{array}$ & $\begin{array}{c}\text { Acetoin } \\
\text { dehydrogenase }^{c}\end{array}$ & Total & \\
\hline \multirow[t]{2}{*}{ CNRZ 483} & - & 52.0 & 1.4 & 53.4 & $50.3(94.2)^{d}$ & $0.1(0.2)$ & $1.4(2.6)$ & 0.0 & 51.8 & $1.6(3.0)$ \\
\hline & + & 53.0 & 5.9 & 58.9 & $45.7(77.6)$ & $0.4(0.7)$ & 0.0 & 0.0 & 46.1 & $12.8(21.7)$ \\
\hline \multirow[t]{2}{*}{$483 \mathrm{~L} 1$} & - & 51.8 & 5.3 & 57.1 & $39.2(68.7)$ & $0.3(0.5)$ & $9.2(16.1)$ & $0.5(0.9)$ & 49.2 & 7.9 (13.8) \\
\hline & + & 51.0 & 6.6 & 57.6 & $24.3(42.2)$ & $0.1(0.2)$ & $6.6(11.5)$ & 0.0 & 31.0 & $26.6(46.2)$ \\
\hline \multirow[t]{2}{*}{ 483L2 } & - & 52.0 & 0.0 & 52.0 & $6.9(13.3)$ & $0.2(0.4)$ & $40.0(77.0)$ & $1.3(2.5)$ & 48.4 & $3.6(6.9)$ \\
\hline & + & 53.2 & 7.3 & 60.5 & $4.5(7.4)$ & $0.1(0.2)$ & $7.8(13.0)$ & $0.9(1.5)$ & 13.3 & $45.2(74.7)$ \\
\hline \multirow[t]{2}{*}{$483 \mathrm{~L} 3$} & - & 52.0 & 3.4 & 55.4 & $8.5(15.3)$ & $0.2(0.4)$ & $38.8(70.0)$ & $1.6(2.9)$ & 49.1 & $6.3(11.4)$ \\
\hline & + & 52.0 & 5.3 & 57.3 & $2.6(4.5)$ & $0.1(0.2)$ & $3.2(5.6)$ & $0.3(0.5)$ & 6.2 & $51.1(89.2)$ \\
\hline
\end{tabular}

${ }^{a}$ Mutants were cultivated at $30^{\circ} \mathrm{C}$, in modified M17 broth, in the presence $(+)$ or absence $(-)$ of oxygen $\left(\mathrm{O}_{2}\right)$.

${ }^{b}$ The difference between NADH produced and NADH consumed.

${ }^{c}$ Enzyme involved in glucose utilization.

${ }^{d}$ Values in parentheses are percentages of NADH consumed via the different pathways related to NADH produced. 
TABLE 4. Enzymatic activities measured in cell extracts of L. lactis subsp. lactis biovar diacetylactis CNRZ 483 and mutants ${ }^{a}$

\begin{tabular}{|c|c|c|c|c|c|c|c|c|}
\hline \multirow{3}{*}{ Enzyme } & \multicolumn{8}{|c|}{ Sp act $(\mathrm{U} / \mathrm{mg} \text { of protein })^{b}$} \\
\hline & \multicolumn{2}{|c|}{ CNRZ 483} & \multicolumn{2}{|c|}{$483 \mathrm{~L} 1$} & \multicolumn{2}{|c|}{$483 \mathrm{~L} 2$} & \multicolumn{2}{|c|}{$483 \mathrm{~L} 3$} \\
\hline & $-\mathrm{O}_{2}$ & $+\mathrm{O}_{2}$ & $-\mathrm{O}_{2}$ & $+\mathrm{O}_{2}$ & $-\mathrm{O}_{2}$ & $+\mathrm{O}_{2}$ & $-\mathrm{O}_{2}$ & $+\mathrm{O}_{2}$ \\
\hline Lactate dehydrogenase & 30.76 & 23.08 & 2.80 & 2.34 & 0.09 & 0.08 & 0.09 & 0.09 \\
\hline NADH oxidase & 0.02 & 0.17 & 0.03 & 0.29 & 0.08 & 0.30 & 0.07 & 0.41 \\
\hline$\alpha$-Acetolactate synthase & 0.18 & 0.65 & 0.17 & 0.50 & 0.26 & 0.49 & 0.16 & 0.64 \\
\hline$\alpha$-Acetolactate decarboxylase & 0.23 & 0.49 & 0.19 & 0.34 & 0.29 & 0.35 & 0.18 & 0.45 \\
\hline Acetoin reductase & $<0.02$ & $<0.02$ & 0.03 & 0.05 & 0.04 & 0.04 & 0.05 & 0.05 \\
\hline Diacetyl reductase & 0.09 & 0.09 & 0.18 & 0.25 & 0.15 & 0.15 & 0.31 & 0.19 \\
\hline
\end{tabular}

\footnotetext{
${ }^{a}$ The strains were grown for $8 \mathrm{~h}$ at $30^{\circ} \mathrm{C}$ in modified M17 broth in the presence or absence of oxygen.

${ }^{b}$ The values are the means of at least three measurements. The standard error was lower than $10 \%$ for all enzymes except $\alpha$-acetolactate decarboxylase, where it
} was lower than $20 \%$.

conditions, however, the latter pathway reoxidizes only a very small quantity of NADH (Table 3 ). It is thus probable that the difference between NADH produced and consumed essentially represents the quantity of NADH reoxidized by NADH oxidase. This enzyme would reoxidize $21.7 \%$ of the NADH produced by strain CNRZ 483, a percentage that increased considerably in mutants 483L1, 483L2, and 483L3 (46.2, 74.7, and $89.2 \%$, respectively).

Enzymatic activities. Some enzymatic activities were assayed at the end of culture to explain the modifications of glucose metabolism in the mutants (Table 4). The results show that under anaerobiosis, the specific activity of lactate dehydrogenase in strain CNRZ 483 was $30.76 \mathrm{U} / \mathrm{mg}$, higher than that observed under aerobiosis $(23.08 \mathrm{U} / \mathrm{mg})$. In the presence or absence of oxygen, this activity decreased considerably in the other strains, in particular mutants 483L2 and 483L3: lactate dehydrogenase activity in this case was less than $0.4 \%$ that of the parental strain. The specific activity of NADH oxidase was higher in the presence of oxygen, especially in mutants 483L2 and $483 \mathrm{~L} 3$ ( 0.30 and $0.41 \mathrm{U} / \mathrm{mg}$, respectively). Similarly, the activities of $\alpha$-acetolactate synthase and $\alpha$-acetolactate decarboxylase were higher in the presence of oxygen in all strains, but no major difference in $\alpha$-acetolactate synthase and $\alpha$-acetolactate decarboxylase activities was noted among the different strains. In the presence or absence of oxygen, acetoin reductase activity in strain CNRZ 483 was lower than 0.02 $\mathrm{U} / \mathrm{mg}$. This activity was higher in the mutants and was between 0.03 and $0.05 \mathrm{U} / \mathrm{mg}$. Diacetyl reductase activity in strain CNRZ $483(0.09 \mathrm{U} / \mathrm{mg})$ was also lower than that of the three mutants, where activities were between 0.15 and $0.31 \mathrm{U} / \mathrm{mg}$.

Kinetic parameters of lactate dehydrogenase. Lactate dehydrogenase activity in mutants 483L2 and 483L3 was approximately 300 times lower than that in the parental strain. It was nevertheless surprising to note that the corresponding lactate production was only 6.5 to 17.6 times lower, depending on the presence or absence of oxygen. This explains why we investigated the saturation of lactate dehydrogenase by pyruvate, $\mathrm{NADH}$, and fructose-1,6-diphosphate in the different strains (Fig. 2). The kinetic constants $\left(K_{m}\right.$ and $\left.V_{\max }\right)$ of lactate dehydrogenase of the different strains are shown in Table 5. The saturation curve of strain CNRZ 483 lactate dehydrogenase by pyruvate was hyperbolic (Fig. 2A). The apparent $K_{m}$ of lactate dehydrogenase in strain $483 \mathrm{~L} 1$ was close to that of the parental strain, but the $V_{\max }$ was about four times lower. The $V_{\max }$ value of the lactate dehydrogenases of mutants 483L2 and 483L3 was lower than that of the parental strain. The affinity of mutant 483L2 lactate dehydrogenase for pyruvate was very low $\left(K_{m}=\right.$ $29.0 \mathrm{mM}$ ), and the saturation curve was sigmoid. When lactate dehydrogenase was saturated by NADH (Fig. 2B), the appar-
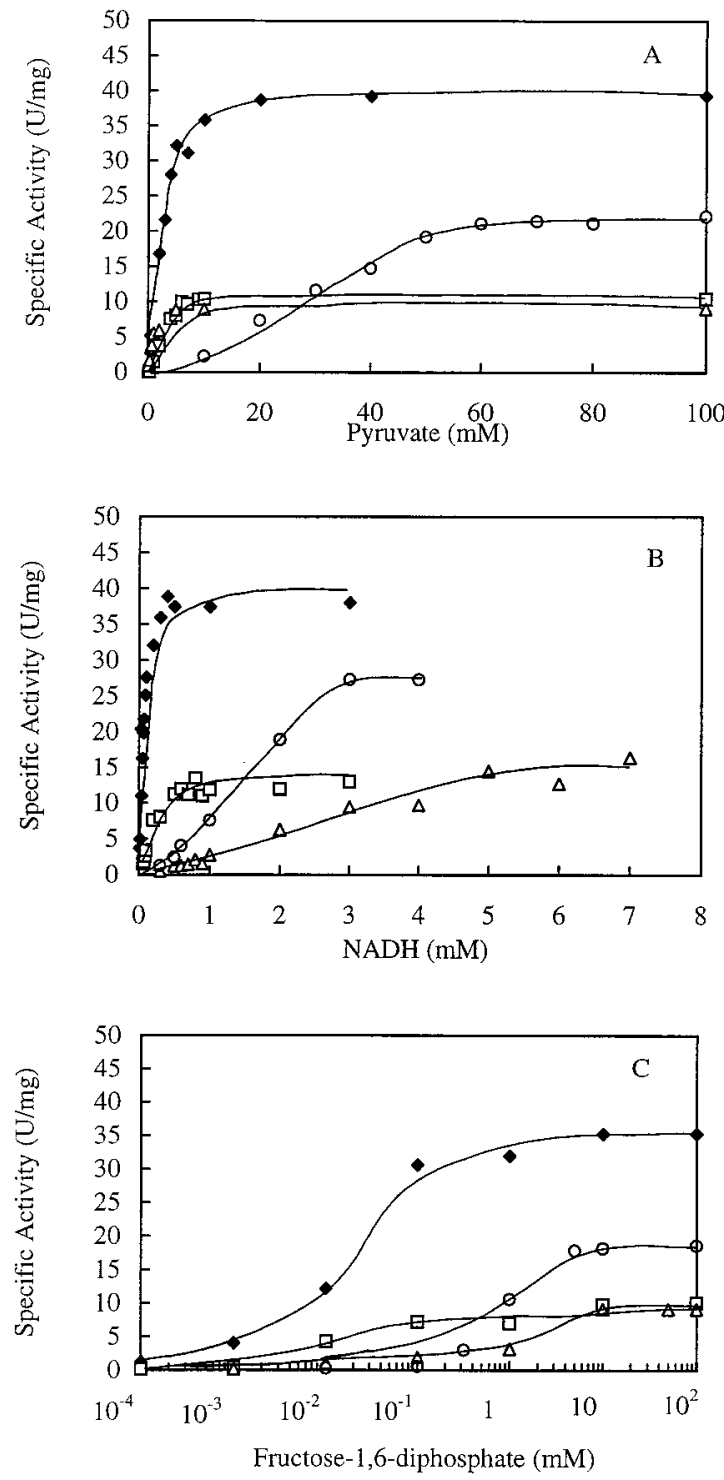

FIG. 2. Saturation of lactate dehydrogenase by pyruvate in the presence of 3 mM NADH and $10 \mathrm{mM}$ fructose-1,6-diphosphate (A), by NADH in the presence of $100 \mathrm{mM}$ pyruvate and $10 \mathrm{mM}$ fructose-1,6-diphosphate (B), and by fructose1,6-diphosphate in the presence of $3 \mathrm{mM}$ NADH and $100 \mathrm{mM}$ pyruvate $(\mathrm{C})$. Assays were conducted in cell extracts obtained after $8 \mathrm{~h}$ of growth at $30^{\circ} \mathrm{C}$ in modified M17 broth. Symbols: $\$$, L. lactis subsp. lactis biovar diacetylactis CNRZ 483; $\square$, mutant 483L1; $\bigcirc$, mutant 483L2; $\triangle$, mutant 483L3. 
TABLE 5. Kinetic constants of lactate dehydrogenase in strain CNRZ 483 and mutants ${ }^{a}$

\begin{tabular}{|c|c|c|c|c|c|c|c|c|}
\hline \multirow[b]{2}{*}{ Substrate } & \multicolumn{2}{|c|}{ CNRZ 483} & \multicolumn{2}{|c|}{$483 \mathrm{~L} 1$} & \multicolumn{2}{|c|}{$483 \mathrm{~L} 2$} & \multicolumn{2}{|c|}{$483 \mathrm{~L} 3$} \\
\hline & $\begin{array}{c}K_{m} \\
(\mathrm{mM})\end{array}$ & $\begin{array}{c}V_{\max } \\
(\mathrm{U} / \mathrm{mg})\end{array}$ & $\begin{array}{c}K_{m} \\
(\mathrm{mM})\end{array}$ & $\begin{array}{c}V_{\max } \\
(\mathrm{U} / \mathrm{mg})\end{array}$ & $\begin{array}{c}K_{m} \\
(\mathrm{mM})\end{array}$ & $\begin{array}{c}V_{\max } \\
(\mathrm{U} / \mathrm{mg})\end{array}$ & $\begin{array}{c}K_{m} \\
(\mathrm{mM})\end{array}$ & $\begin{array}{c}V_{\max } \\
(\mathrm{U} / \mathrm{mg})\end{array}$ \\
\hline Pyruvate & 2.6 & 40 & 3.0 & 10.6 & 29.0 & 21.3 & 1.0 & 9.0 \\
\hline NADH & 0.07 & 35.8 & 0.17 & 12.0 & 1.90 & 27.5 & 2.90 & 16.0 \\
\hline Fructose-1,6-diphosphate & 0.03 & 36.0 & 0.14 & 10.0 & 0.89 & 18.5 & 1.10 & 9.0 \\
\hline
\end{tabular}

${ }^{a}$ Assays were conducted with cell extracts obtained after $8 \mathrm{~h}$ of culture at $30^{\circ} \mathrm{C}$ in modified M17 broth.

ent $K_{m}$ and $V_{\max }$ of the CNRZ 483 enzyme were $0.07 \mathrm{mM}$ and $35.8 \mathrm{U} / \mathrm{mg}$, respectively. The lactate dehydrogenases of mutants 483L1, 483L2, and 483L3 had higher apparent $K_{m}$ values than the parental strain and lower $V_{\max }$ values (Table 5). There were also differences in lactate dehydrogenase saturation by fructose-1,6-diphosphate (Fig. 2C). The lactate dehydrogenase saturation curves of all the strains were sigmoid. The apparent $K_{m}$ values in the three mutants were higher than in the parental strain, while $V_{\max }$ values were lower.

\section{DISCUSSION}

This work describes a method for isolating mutants of lactococci that can produce diacetyl and acetoin from glucose in the absence of citrate. This metabolic shunt is due primarily to the change of an enzyme, lactate dehydrogenase. The kinetic study of lactate dehydrogenases of the different mutants has shown that treatment with the mutagen did not totally inactivate the enzyme but rather modified its properties. As in the case of all lactococci, the lactate dehydrogenases of the mutants and the parental strain were active only in the presence of fructose-1,6-diphosphate $(9,14,17,25)$. When the enzyme was saturated by pyruvate, the apparent $K_{m}$ of strain CNRZ 483 lactate dehydrogenase $(2.6 \mathrm{mM})$ was higher than that reported by Crow and Pritchard (1.5 mM) (14). The $K_{m}$ and $V_{\max }$ values of the mutants differed from those of the parental strain. In mutant 483L2, the $K_{m}$ was very high, reflecting a low affinity for pyruvate. The apparent $K_{m}$ of CNRZ 483 lactate dehydrogenase for NADH was the same as that reported by Crow and Pritchard $(0.08 \mathrm{mM})$ (14). Nevertheless, the affinity of the mutant lactate dehydrogenases for NADH was lower, particularly in mutant 483L3, whose apparent $K_{m}$ was about 40 times higher than that of the parental strain. Regardless of the strain, the curve of lactate dehydrogenase saturation by fructose-1,6diphosphate was sigmoid, suggesting a positive cooperativity in fructose-1,6-diphosphate binding. Enzyme affinity for fructose1,6-diphosphate was lower in the mutants, in particular mutant 483L3, whose apparent $K_{m}$ was about 40 times higher than that of the parental strain.

Under anaerobic conditions, the mutants produced less lactate than the parental strain did, probably because of their lower lactate dehydrogenase activity. In contrast to the parental strain, which mainly used lactate dehydrogenase to regenerate NAD, the mutants reoxidized a portion of the coenzyme for ethanol synthesis, thus producing large quantities of formate. In comparison to the parental strain, the quantity of ethanol produced was approximately half of the lactate deficit (lactate produced by the parental strain minus lactate produced by each mutant), since 2 mol of NAD was regenerated per mol of ethanol produced. Mutants 483L2 and 483L3 reoxidized more than $70 \%$ of the NADH by this pathway. These mutants also regenerated a small quantity of NAD by the formation of 2,3-butanediol. Formate and ethanol production by lactate dehydrogenase-negative mutants had been reported by Platteuw et al. (36). Pyruvate is considered to be toxic for the cell, explaining why pyruvate not used to regenerate NAD was shunted towards the synthesis of other products such as acetate and acetoin in the mutants. As was observed for strain CNRZ 483, mutant 483L1 produced no acetoin. Attenuation of lactate dehydrogenase in this mutant was probably not sufficient to yield the synthesis of large quantities of acetoin under anaerobiosis. In addition, no strain did produce diacetyl under anaerobic conditions. It is currently accepted that diacetyl formation from $\alpha$-acetolactate occurs only in the presence of oxygen or under oxidizing conditions $(15,43)$.

All strains produced less lactate under aerobic conditions than in the absence of oxygen, which probably resulted from the reduced activity of lactate dehydrogenase in the presence of oxygen. A recent study has shown that lactate dehydrogenase activity in strain CNRZ 483 decreased as the oxygen concentration increased (6). Smart and Thomas (37) also showed that in the presence of oxygen, the intracellular concentration of fructose-1,6-diphosphate was lower, thereby resulting in decreased lactate dehydrogenase activity in vivo. In the presence of oxygen, a portion of the NAD is regenerated via NADH oxidase. As observed by Bruhn and Collins (10) and by Bassit et al. (3), this enzyme activity increases in the presence of oxygen. Strain CNRZ 483 reoxidized $21.7 \%$ of NADH with this enzyme, and the percentage was higher in the mutants (up to $89.2 \%$ in strain 483L3). The quantities of ethanol and formate produced decreased in the presence of oxygen, probably because of the oxygen sensitivity of pyruvate formate lyase (1). Larger quantities of diacetyl and acetoin were produced in the presence of oxygen. Since lactate and ethanol production were lower, a larger quantity of pyruvate was available for the synthesis of diacetyl and acetoin. Furthermore, as observed by Cogan et al. (12) and Bassit et al. (3), $\alpha$-acetolactate synthase activity in all strains increased under aerobiosis, thus favoring acetoin synthesis. In mutants 483L2 and 483L3, almost $80 \%$ of glucose was transformed to diacetyl, acetoin, and 2,3-butanediol. It was also shown that the activity of $\alpha$-acetolacate decarboxylase increased in all the strains in the presence of oxygen. All lactate dehydrogenase-attenuated mutants produced much more acetoin than diacetyl, probably as a result of their $\alpha$-acetolactate decarboxylase activity. This is why this type of mutant cannot be selected by use of a diacetyl-specific colorimetric reaction on petri dishes, such as that described by Monnet et al. (31). The screening method used in the present work leads to the simultaneous detection of the production of diacetyl and, above all, acetoin, which predominates in lactate dehydrogenase-attenuated mutants.

In summary, this work has led to the isolation and characterization of $L$. lactis subsp. lactis biovar diacetylactis CNRZ 483 mutants that produced diacetyl and acetoin from glucose in the absence of citrate. The mutations caused a severe attenuation of lactate dehydrogenase activity. Genetic engineering inactivation of the gene coding for lactate dehydrogenase has been described by Platteeuw et al. (36) and Gasson et al. (18). 
The principal difference between our work and that of these authors is that we did not select mutants lacking lactate dehydrogenase activity but rather those exhibiting various levels of attenuation of this enzyme activity. This will enable mutants with a desired equilibrium between acidifying activity and aroma production to be selected. In addition, the kinetic properties of lactate dehydrogenase from mutants, i.e., affinity for pyruvate, NADH, and fructose-1,6-diphosphate, were different from those of the parental strain. This is probably due to a structural modification on the enzyme in the mutants. To confirm this hypothesis, it will be necessary to study the sequences of the gene coding for lactate dehydrogenase in the mutants and the parental strain. In addition, the comparison between gene sequences and the corresponding kinetic properties of lactate dehydrogenase should enable us to better understand the structure-function relationship of this enzyme.

The application of these mutants in the production of dairy products is being studied. A complementary approach would involve selecting $\alpha$-acetolactate decarboxylase-negative mutants from these strains. Theoretically, these double mutants would produce $\alpha$-acetolactate and diacetyl at the expense of acetoin.

\section{ACKNOWLEDGMENTS}

This research was supported by contract AIR3-CT94-2010 from the European Union. H. Boumerdassi was financed by the Algerian Higher Education Ministry and the French Foreign Affairs Ministry.

We thank P. Tailliez for advice concerning the RAPD method and J. Tremblay and G. Yonnet for technical assistance. We also thank E. Latrille for helpful discussions.

\section{REFERENCES}

1. Abbe, K., S. Takahashi, and T. Yamada. 1982. Involvement of oxygensensitive pyruvate formate-lyase in mixed-acid fermentation by Streptococcus mutans under strictly anaerobic conditions. J. Bacteriol. 152:175-182.

2. Anders, R. F., D. M. Hogg, and G. R. Jago. 1970. Formation of hydrogen peroxide by group $\mathrm{N}$ streptococci and its effect on their growth and metabolism. Appl. Microbiol. 19:608-612.

3. Bassit, N., C. Y. Boquien, D. Picque, and G. Corrieu. 1993. Effect of oxygen concentration on diacetyl and acetoin production by Lactococcus lactis subsp. lactis biovar diacetylactis. Appl. Environ. Microbiol. 59:1893-1897.

4. Bassit, N., C. Y. Boquien, D. Picque, and G. Corrieu. 1995. Effect of temperature on diacetyl and acetoin production by Lactococcus lactis subsp. lactis biovar diacetylactis CNRZ 483. J. Dairy Res. 62:123-129.

5. Benson, K. H., J. J. Godon, P. Renault, H. G. Griffin, and M. J. Gasson. 1996. Effect of $i l v B N$-encoded $\alpha$-acetolactate synthase expression on diacetyl production in Lactococcus lactis. Appl. Microbiol. Biotechnol. 45:107-111.

6. Boumerdassi, H., M. Desmazeaud, C. Monnet, C. Y. Boquien, and G. Corrieu. 1996. Improvement of diacetyl production by Lactococcus lactis ssp. lactis CNRZ 483 through oxygen control. J. Dairy Sci. 79:775-781.

7. Boumerdassi, H., C. Monnet, M. Desmazeaud, and G. Corrieu. Effect of citrate on production of diacetyl and acetoin by Lactococcus lactis ssp. lactis CNRZ 483 cultivated in the presence of oxygen. J. Dairy Sci., in press.

8. Bradford, M. M. 1976. A rapid and sensitive method for quantification of microgram quantities of protein utilizing the principal of protein-dye-binding. Anal. Biochem. 72:248-254.

9. Brown, A. T., and C. L. Wittenberger. 1972. Fructose-1,6-diphosphate-dependent lactate dehydrogenase from a cariogenic streptococcus: purification and regulatory properties. J. Bacteriol. 110:604-615.

10. Bruhn, J. C., and E. B. Collins. 1970. Reduced nicotinamide adenine dinucleotide oxidase of Streptococcus diacetylactis. J. Dairy Sci. 53:857-860.

11. Cogan, T. M. 1981. Constitutive nature of the enzymes of citrate metabolism in Streptococcus lactis ssp. diacetylactis. J. Dairy Res. 48:489-495.

12. Cogan, T. M., D. Walsh, and S. Condon. 1989. Impact of aeration on the metabolic end-products formed from glucose and galactose by Streptococcus lactis. J. Appl. Bacteriol. 66:77-84

13. Crow, V. L. 1990. Properties of 2,3-butanediol dehydrogenase from Lactococcus lactis subsp. lactis in relation to citrate fermentation. Appl. Environ. Microbiol. 56:1656-1665.

14. Crow, V. L., and G. G. Pritchard. 1977. Fructose 1,6-diphosphate-activated L-lactate dehydrogenase from Streptococcus lactis: kinetic properties and factors affecting activation. J. Bacteriol. 131:82-91.

15. De Man, J. C. 1959. The formation of diacetyl and acetoin from $\alpha$-acetolactic acid. Rec. Trav. Chim. Pays-Bas Belg. 78:480-486.

16. De Man, J. C., M. Rogosa, and M. E. Sharpe. 1960. A medium for cultivation of lactobacilli. Appl. Bacteriol. 23:130-135.

17. Garvie, E. I. 1980. Bacterial lactate dehydrogenases. Microbiol. Rev. 44:106139.

18. Gasson, M. J., K. Benson, and H. Griffin. 1996. Metabolic engineering of the Lactococcus lactis diacetyl pathway. Lait 76:33-40.

19. Gibson, T. D., S. M. Parker, and J. R. Woodward. 1991. Purification and characterization of diacetyl reductase from chicken liver and Streptococcus lactis and enzymic determination of diacetyl and diketones. Enzyme Microb. Technol. 13:171-179.

20. Godon, J. J., M. C. Chopin, and S. D. Ehrlich. 1992. Branched-chain amino acid biosynthesis genes in Lactococcus lactis subsp. lactis. J. Bacteriol. 174: 6580-6589.

21. Goupil, N., G. Corthier, S. D. Ehrlich, and P. Renault. 1996. Imbalance of leucine flux in Lactococcus lactis and its use for the isolation of diacetyloverproducing strains. Appl. Environ. Microbiol. 62:2636-2640.

22. Harvey, R. J., and E. B. Collins. 1962. Citrate transport system of Streptococcus diacetylactis. J. Bacteriol. 83:1005-1009.

23. Hugenholtz, J. 1993. Citrate metabolism in lactic bacteria. FEMS Microbiol. Rev. 12:165-178.

24. Hugenholtz, J., and M. J. C. Starrenburg. 1992. Diacetyl production by different strains of Lactococcus lactis subsp. lactis var. diacetylactis and Leuconostoc spp. Appl. Microbiol. Biotechnol. 38:17-22.

25. Jonas, H. A., R. F. Anders, and G. R. Jago. 1972. Factors affecting the activity of the lactate dehydrogenase of Streptococcus cremoris. J. Bacteriol. 111:397-403.

26. Jordan, K. N., and T. M. Cogan. 1988. Production of $\alpha$-acetolactate by Streptococcus diacetylactis and Leuconostoc spp. J. Dairy Res. 55:227-238.

27. Kuila, R. K., and B. Ranganathan. 1977. Ultraviolet light-induced mutants of Streptococcus lactis subspecies diacetylactis with enhanced acid- or flavorproducing abilities. J. Dairy Sci. 61:379-383.

28. Libudzisz, Z., and E. Galewska. 1991. Citrate metabolism in Lactococcus lactis subsp. lactis var. diacetylactis strains. Die Nahrung. 35:611-618.

29. McKay, L. L., and K. A. Baldwin. 1973. Altered metabolism in a Streptococcus lactis C2 mutant deficient in lactic dehydrogenase. J. Dairy Sci. 57:181-186.

30. Monnet, C., P. Schmitt, and C. Diviès. 1994. Diacetyl production in milk by an $\alpha$-acetolactic acid-accumulating strain of Lactococcus lactis ssp. lactis biovar diacetylactis. J. Dairy Sci. 77:2916-2924.

31. Monnet, C., P. Schmitt, and C. Diviès. 1997. Development and use of a screening procedure for production of $\alpha$-acetolactate by Lactococcus lactis subsp. lactis biovar diacetylactis strains. Appl. Environ. Microbiol. 63:793-795.

32. Pack, M. Y., E. R. Vedamuthu, W. E. Sandine, P. R. Elliker, and H. Leesment. 1967. Effect of temperature on growth and diacetyl production by aroma bacteria single- and mixed-strain lactic cultures. J. Dairy Sci. 51:339-344.

33. Petit, C., F. Vilchez, and R. Marczak. 1989. Influence of citrate on the diacetyl and acetoin production by fully grown cells of Streptococcus lactis subsp. diacetylactis. Curr. Microbiol. 19:319-323.

34. Phalip, V., C. Monnet, P. Schmitt, P. Renault, J. J. Godon, and C. Diviès. 1994. Purification and properties of the $\alpha$-acetolactate decarboxylase from Lactococcus lactis subsp. lactis NCDO 2118. FEBS Lett. 351:95-99.

35. Phalip, V., P. Schmitt, and C. Diviès. 1994. A method for screening diacetyl and acetoin-producing bacteria on agar plates. J. Basic Microbiol. 34:277-280.

36. Platteeuw, C., J. Hugenholtz, M. Starrenburg, I. van Alen-Boerrigter, and W. de Vos. 1995. Metabolic engineering of Lactococcus lactis: influence of the overproduction of $\alpha$-acetolactate synthase in strains deficient in lactate dehydrogenase as a function of culture conditions. Appl. Environ. Microbiol. 61:3967-3971.

37. Smart, J. B., and T. Thomas. 1987. Effect of oxygen on lactose metabolism in lactic streptococci. Appl. Environ. Microbiol. 53:533-541.

38. Starrenburg, M. J. C., and J. Hugenholtz. 1991. Citrate fermentation by Lactococcus and Leuconostoc spp. Appl. Environ. Microbiol. 57:3535-3540.

39. Swindell, S. R., K. H. Benson, H. G. Griffin, P. Renault, S. D. Ehrlich, and M. J. Gasson. 1996. Genetic manipulation of the pathway for diacetyl metabolism in Lactococcus lactis. Appl. Environ. Microbiol. 62:2641-2643.

40. Tailliez, P., P. Quénée, and A. Chopin. 1996. Estimation de la diversité parm les souches de la collection CNRZ: application de la RAPD à un groupe de lactobacilles. Lait 76:147-158.

41. Terzaghi, B. E., and W. E. Sandine. 1975. Improved medium for lactic streptococci and their bacteriophages. Appl. Microbiol. 29:807-813.

42. Thomas, T. D. 1976. Regulation of lactose fermentation in group N streptococci. Appl. Environ. Microbiol. 32:474-478.

43. Verhue, W. M., and F. S. B. Tjan. 1991. Study of citrate metabolism of Lactococcus lactis subsp. lactis biovar diacetylactis by means of ${ }^{13} \mathrm{C}$ nuclear magnetic resonance. Appl. Environ. Microbiol. 57:3371-3377.

44. Walsh, B., and T. M. Cogan. 1974. Further studies on the estimation of diacetyl by the methods of Prill and Hammer and Owades and Jakovac. J. Dairy Res. 41:31-35.

45. Welsh, J., and M. McLelland. 1990. Fingerprinting genomes using PCR with arbitrary primers. Nucleic Acids Res. 18:7213-7218.

46. Westerfeld, W. W. 1945. A colorimetric determination of blood acetoin J. Biol. Chem. 161:495-502.

47. Williams, J. G. K., A. R. Kubelick, K. J. Rafalski, and S. V. Tingey. 1990. DNA polymorphisms amplified by arbitrary primers are useful as genetic markers. Nucleic Acid Res. 18:6531-6535. 